\title{
Propagandas, alienação e sedução: o rompimento ontológico homem-trabalho como fundamento do protagonismo social das imagens
}

Propagandas, alienation and seduction: the humanwork ontological break off as a foundation of the social protagonism of the images

\author{
Marsiel Pacíficol \\ Luiz Roberto Gomes ${ }^{2}$
}

Resumo: A análise do capitalismo feita por Marx constituiu ferramentas fundamentais para o diagnóstico da estrutura e do funcionamento do capital. Todavia, pertencente a seu tempo histórico, tal análise suscita a atualização para um sistema fortemente determinado pela sua dimensão subjetiva. Para compreender esse movimento, por meio de uma revisão bibliográfica, apontaremos na ruptura da dimensão ontológica do trabalho propiciada pelo trabalho alienado típico do capitalismo a condicionante de esvaziamento subjetivo que possibilitou o avançar da imagem, mediada pelas propagandas, como potência da forma contemporânea do capital.

Palavras-chave: propagandas; capital; imagem; alienação; ontologia.

Abstract: The analysis of capitalism, made by Marx, constituted fundamental tools for the diagnosis of the structure and functioning of capital. However, belonging to its historical time, this analysis raises the update to a system strongly determined by its subjective dimension. To understand this movement, through a bibliographical review, we will point out the rupture of the ontological dimension of work, propitiated by the alienated work typical of capitalism, the condition

1 Universidade Estadual de Ponta Grossa (UEPG). Ponta Grossa, PR, Brasil. https://orcid.org/0000-0002-2013-2073.E-mail: marsiellp@gmail.com

2 Universidade Federal de São Carlos (UFSCar). São Carlos, SP, Brasil.

https://orcid.org/0000-0002-8867-7897. E-mail: luizroberto.gomes@gmail.com 
102 PROPAGANDAS, ALIENAÇÃO E SEDUÇÃO

of subjective emptying that allowed the advancement of the image, mediated by advertisements, as a power of the contemporary form of capital.

Keywords: propagandas; capital; image; alienation; ontology. 


\section{Introdução}

As propagandas inundaram nosso cotidiano pela imagem. O meio desse processo tem seus condicionantes sociais e históricos arraigados na nossa cultura, o que determina a aceitação quase orgânica da relação de consumo das imagens. Não somente as propagandas, mas até mesmo o modo como nos comunicamos entre sujeitos tende, contemporaneamente, à modalidade imagética. Tal constatação deve ser compreendida não somente a partir da centralidade das mesmas nas nossas relações simbólicas com os produtos, mas, sobretudo, no modo e na intensidade como as recebemos e nos vinculamos a elas. Compreender o protagonismo da imagem passa pela constatação de quais espaços ela ocupa em nossa subjetividade e, por consequência, qual a origem dos mesmos. Assim, a constatação do espetáculo enquanto centro da vida social demanda uma análise profunda de seus caminhos. Se tivéssemos que mapear o fio condutor que nos guia historicamente do diagnóstico de Karl Marx às atualizações propostas por Guy Debord e Christoph Türcke, poderíamos afirmar que as imagens detêm o protagonismo desse processo. A centralidade das imagens, cujo percurso se inicia nas propagandas como um adorno secundário da mercadoria, tem, por pressão concorrencial do próprio mercado e por uma série de convergências históricas, como a falência do modelo fordista-keynesiano, o desenvolvimento tecnológico e, sobretudo, a popularização das máquinas fotográficas, um vasto e profícuo campo para se desenvolver, a ponto de se afirmar: "essa estetização aderiu ao capitalismo; é a sua pele e não seu envoltório” (TÜRCKE, 2010, p. 11).

Desse modo, este artigo visa apresentar, pela dinâmica das relações históricas, como as propagandas vão, processualmente, ganhando poder no campo cultural, determinando não só a relação de valor da mercadoria, mas estabelecendo sua relação com o homem por meio de uma dimensão ontológica, substituindo a cindida relação homem-trabalho, esvaziada em seu valor simbólico pelo modo de produção capitalista.

A verificação desse processo histórico de inversão, no qual o espírito social detém a primazia sobre sua materialidade, arroga características 
subjetivas específicas que, em maior ou menor medida, atingem todos os sujeitos imersos nesse contexto histórico.

Entretanto, e como já exposto por Debord, o imperativo domínio da dimensão estética do capital sobre suas formas materiais tem como origem fundamental as configurações específicas da relação de trabalho impostas pelo próprio sistema. Como explica o autor:

O trabalhador não se produz a si mesmo, produz uma força independente. O sucesso dessa produção, sua abundância, volta para o produtor como abundância da despossessão. Com a acumulação de seus produtos alienados, o tempo e o espaço de seu mundo se tornam estranhos para ele. O espetáculo é o mapa desse novo mundo, mapa que corresponde exatamente a seu território. As forças que nos escaparam mostram-se a nós em todo o seu vigor (DEBORD, 1997, p. 24).

O homem sujeitado pelo poder hipnótico de seus produtos é um estágio histórico cujo antecedente fundamental é o desmantelamento progressivo dos vínculos ontológicos do homem com o produto de seu trabalho. Somente pelas forças semiformativas da alienação se dão as condições espirituais para que se repliquem formas de dominação, daquilo que, a priori, deveria ser de uso do homem, segundo seus desígnios.

Assim, a análise do fortalecimento subjetivo do caráter imagético do espetáculo está circunscrita à depreciação objetiva da dimensão identitária do trabalho, no qual o homem construía signos de valor para si e para a coisa - ao alienar-se da coisa, alienou-se de si. É no tempo histórico da perda do chão da relação homem-trabalho que a imagem ganha forças para nos impelir ao espetáculo que detém, inclusive, a primazia sobre nossa vida privada.

Se a premissa da primazia das imagens parece se sustentar pelas observações de nosso tempo, tal inversão ocorre na base da infraestrutura social e de implicações objetivas da sofisticação do modo capitalista de produção. Para a compreensão desses processos, há de se considerar a relação dialética entre dois campos de forças: a relação homem-trabalho e a relação entre o concreto e o abstrato na mercadoria. Tal conjugação 
nos permite estabelecer os vínculos da dinâmica social que impuseram novos parâmetros de um lado a outro e culminaram no atual estágio do capital, da sociedade e, sobretudo, da cultura.

Dessa maneira, observaremos, na primeira seção deste artigo, como o modelo de trabalho típico do capital, analisado por Marx, cindiu a relação ontológica homem-trabalho, criando um espaço no espírito humano que foi, pouco a pouco, sendo sublimado pelas relações simbólicas da produção do desejo de consumo da mercadoria na estetização das propagandas.

Na segunda seção, demonstraremos como tal lógica determina uma nova compreensão das relações de valor da mercadoria, que, para além do modelo de quantum proposto por Marx, demanda fatores subjetivos novos e urgentes ao entendimento de nossos dias.

\section{Ontologia do trabalho e alienação: a produção das fragilidades do sujeito}

Como premissa de sua análise do capital, está em Marx a compreensão de que a relação entre homem e trabalho tem fundamental importância, não somente no modo de organização e desenvolvimento do labor, mas também enquanto processo dialético, produto e produtor do sujeito histórico. A ontologia do trabalho em Marx remete do capital ao estágio primitivo de nossa espécie, no qual o homem, como animal, e assim como todo animal, sempre teve sua sobrevivência atrelada às condições de sua existência física em relação ao mundo. Seu eternum continuum entre a extremidade frágil do viver e morrer é, e sempre será, pétreo na constituição da natureza do homem.

Exercer sua vontade sobre tal relação significa criar condições positivas de combate às adversidades em prol do prolongamento de sua existência material em âmbito individual e coletivo. Assim, nossa espécie se fez e prosperou sobre a face da Terra em proporção à capacidade de intervenção sobre a natureza. Há, ainda, no perder de vista do futuro histórico, a certeza de que o trabalho será sempre o modo 
de transformação da natureza pelo homem para satisfazer suas necessidades e para constantemente se recriar na relação de sua produção material e simbólica no mundo.

O homem estabelece com o trabalho uma relação dialética profunda que, para além da materialidade objetiva do trabalho e seus produtos, lhe permite, no exercício de modificação da natureza, estabelecer processos de ressignificação subjetiva de si mesmo. Como explica Marx:

Antes de tudo, o trabalho é um processo entre o homem e a Natureza, um processo em que o homem, por sua própria ação, media, regula e controla seu metabolismo com a Natureza. Ele mesmo se defronta com a matéria natural como uma força natural. Ele põe em movimento as forças naturais pertencentes a sua corporalidade, braços e pernas, cabeça e mão, a fim de apropriar-se da matéria natural numa forma útil para sua própria vida. Ao atuar, por meio desse movimento, sobre a Natureza externa a ele e ao modificá-la, ele modifica, ao mesmo tempo, sua própria natureza (MARX, 1996, p. 297).

Para além da resolução das questões urgentes de nossa existência, na observância da genealogia de nossa espécie, podemos apontar como é correlato nosso desenvolvimento social com nossa capacidade de trabalho. À medida que conseguíamos desenvolver trabalhos e tarefas mais complexas, a humanidade florescia desde a transição evolucionista de nossos antepassados hominídeos para aquilo que hoje consideramos o homem moderno. Nesse sentido, não podemos perder de vista que foi sobre a adaptação cognitiva de nossos semelhantes para atividades complexas que desenvolvemos nossas abstrações mais densas e que tal relação foi impulsionada pelas mediações simbólicas do trabalho exercido sobre o ser humano. Como demonstra Engels:

Graças à cooperação da mão, dos órgãos da linguagem e do cérebro, não só em cada indivíduo, mas também na sociedade, os homens foram aprendendo a executar operações cada vez mais complexas, a propor-se e alcançar objetivos cada vez mais elevados. O trabalho mesmo se diversificava e aperfeiçoava de geração em geração, estendendo-se cada vez a novas atividades. À caça e à pesca veio juntar-se a agricultura e, mais tarde, a fiação e a tecelagem, a elaboração de metais, a olaria e a 
navegação. Ao lado do comércio e dos ofícios apareceram, finalmente, as artes e as ciências; das tribos saíram as nações e os Estados. Apareceram o direito e a política e, com eles, o reflexo fantástico das coisas no cérebro do homem: a religião (ENGELS, 1990, p. 29).

No princípio das organizações sociais mais rudimentares, o intervir intencional e metódico sobre a natureza ocorria de modo a atender às necessidades físicas e espirituais do homem. Alimentar-se, abrigar-se, indumentar-se para ritos e cultos: para tudo havia um propósito, que era a primazia do trabalho como instrumento de satisfação das necessidades pessoais e grupais. Nesse sentido, observamos o trabalho como um modus operandi da humanidade para alcançar seus propósitos e se defender de forças alheias. Sendo assim, o produto do trabalho humano visava atender às necessidades imediatas ou socialmente constituídas pelas produções culturais. Ainda assim, tais produções objetivavam equacionar demandas de caráter objetivo, como a intervenção espiritual sobre a natureza como forma de dominação e de defesa humana contra processos cujo controle não se detinha.

Nessa relação, há de se considerar ainda que a perspectiva marxiana compreende que o trabalho exerce a primazia do movimento dialético. Todo trabalho humano era um "para" cuja finalidade estava alocada fora de sua essência; o trabalho seria um servo das necessidades humanas e só enquanto tal existiria. Para além disso, no tocante à relação individual, o produto do trabalho era, em geral, uma demanda direta de seu trabalhador.

Nessa configuração primitiva do trabalho, há ainda a dimensão da liberdade, inclusa no exercício abstrato de determinação “do que" e "de como" o produto final do trabalho seria criado - determinação essa que está diretamente a caráter da vontade e da dimensão técnica do trabalhador.

Com o surgimento do capitalismo, o vínculo estabelecido entre homem e trabalho é ressignificado a partir de novas relações. As intervenções e mediações sobre o exercício da vontade e da criação do trabalhador sobre seu trabalho possibilitaram a formação de uma relação 
adoecida em sua potencialidade ontológica. Se os modos de produção específicos de sua época histórica determinam as relações entre sujeito e trabalho, há de se considerar as peculiaridades do capital, cujo sistema está, para a análise materialista histórica dialética, alicerçada nas relações antagônicas de classes sociais.

Assim, características novas se determinam no processo produtivo. Entre elas, podemos destacar a expropriação do produto final do trabalho ao trabalhador, a alienação do trabalho fragmentário, o controle de acesso e regime de trabalho empoderado pelo capitalista e a transformação do produto em mercadoria; mas, sobretudo, e no que concerne ao nosso objeto de análise, destaca-se a dimensão do fetiche da mercadoria e a produção subjetiva da necessidade do consumo, inaugurados pelas peculiaridades históricas do processo de desenvolvimento do capital.

Ao contrário do que observamos no auge do desenvolvimento do capitalismo, a respeito do qual escrevem Karl Marx e Friedrich Engels, o resgate da dimensão ontológica do trabalho demonstra que a essencialidade humana se realiza na medida em que o sujeito se atrela ao trabalho. Todavia, a alienação e a expropriação subjetiva inerentes ao capital fizeram com que justamente o processo que torna o homem sujeito histórico autodeterminado se tornasse seu principal agente de degradação histórica.

Quando se rompe, entre o homem e o produto de seu trabalho, todos os vínculos subjetivos da criação e expressão de si, a carga da exterioridade absoluta passa a determinar um caráter de estranhamento na relação sujeito-objeto. O momento objetivo que permitia a manifestação pessoal se desfaz no modo de produção do capital, dando espaço a um modelo cujo trabalho se remete somente à sua objetividade, a um "fazer" sem "conceber".

O agravamento desse quadro ocorre pelo rompimento do vínculo de pertencimento que era natural às outras relações de trabalho. No modelo capitalista, aquilo que é produzido pelo trabalhador não lhe pertence; está destinado a outro sujeito que lhe empregará outra utilidade, totalmente alheia ao sujeito produtor da mercadoria. 
Desse modo, a prática da dominação se esvazia completamente de seu sentido original. Se a intervenção do homem no mundo permite a dominação deste por aquele, tal relação só se dá em decorrência da destinação e intenção de seu produto final. Porém, quando o produto final de um trabalho está à margem dessa relação, o produto se absolutiza em relação ao sujeito, conferindo àquele um caráter autônomo de mercadoria em simultaneidade com o processo de coisificação do sujeito. Tal inversão determina o desassenhoreamento do homo faber, cujos produtos de seu trabalho serviam para seus fins. No contexto do desenvolvimento do capital, ao sujeito alienado de seu trabalho resta o papel de pequeno intermediário, componente necessário da etapa produtiva - como tal, deve servir e se guiar pelos caminhos da mercadoria, no estágio da vida social no qual "as coisas são, em si e para si, externas ao homem, e portanto, alienáveis” (MARX, 1996, p. 212). Esse processo de inversão promovido pelo capital, no qual os homens se coisificam e as coisas ganham características exclusivamente humanas e se absolutizam, é explicado por Jacob Gorender:

Desvenda-se o caráter alienado de um mundo em que as coisas se movem como pessoas e as pessoas são dominadas pelas coisas que elas próprias criam. Durante o processo de produção, a mercadoria ainda é matéria que o produtor domina e transforma em objeto útil. Uma vez posta à venda no processo de circulação, a situação se inverte: o objeto domina o produtor. O criador perde o controle sobre sua criação e o destino dele passa a depender do movimento das coisas, que assumem poderes enigmáticos. Enquanto as coisas são animizadas e personificadas, o produtor se coisifica. Os homens vivem, então, num mundo de mercadorias, um mundo de fetiches (GORENDER, 1996, p. 34).

A intervenção sobre a natureza possibilitava ao homem se imprimir subjetivamente sobre a mesma por meio de seu produto. Esse processo se fundamenta no capital por meio de outra lógica, como demonstra Marx:

Aquele que produz um objeto para seu uso pessoal e direto, para consumi-lo, cria um produto, mas não uma mercadoria. Como produtor que se 
mantém a si mesmo, nada tem com a sociedade. Mas, para produzir uma mercadoria, não só se tem de criar um artigo que satisfaça a uma necessidade social qualquer, como também o trabalho nele incorporado deverá representar uma parte integrante da soma global de trabalho invertido pela sociedade. Tem que estar subordinado à divisão de trabalho dentro da sociedade. Não é nada sem os demais setores do trabalho, e, por sua vez, é chamado a integrá-los (MARX, 1996, p. 92).

Tal inversão produz um esvaziamento simbólico da dimensão do trabalho, cujo novo lócus será central na análise do capitalismo transnacional para que possamos entender o cerne histórico da espetacularização.

Apesar da possibilidade de o hodierno estágio social do espetáculo demandar uma atualização na análise ontológica do homem, está em voga o advento da imagem como tessitura social encontrou um campo profícuo a partir da alienação do sujeito proveniente do modo de trabalho capitalista. Denunciado por Marx, esse modelo mantém suas bases de alienação e expropriação. Esvaziado, o homem moderno padece por ter perdido os vínculos que, em última instância, fundamentariam as bases para a constituição de uma singularidade. Se essas bases partissem do exercício da autonomia e do espírito crítico, poderiam resistir ao amplo processo de massificação espetaculosa que presenciamos.

\section{Da materialidade à subjetividade: a produção do desejo de consumo como determinante do quantum da mercadoria}

A estrutura do trabalho no capital, para além dos rompimentos ontológicos da relação homem-trabalho, propicia o surgimento histórico do sujeito interceptor dessa relação: o burguês, aquele para quem se vende a força produtiva. Na medida em que o processo produtivo é entrecruzado por um novo sujeito histórico, a determinação da necessidade à qual o produto responderá não está, em medida nenhuma, ligada ao seu produtor, mas é reconhecida no interior da lógica economicista, que, já em Marx, concebia a mercadoria como forma de satisfazer necessidades humanas, do corpo e do espírito (MARX, 1996, p. 165). A ordem dos 
fatores expostas por Marx responde ao seu tempo. No entanto, há de se notar que, historicamente, o processo de produção da necessidade subjetiva do consumo ganhou a dimensão de protagonismo no corpo do capitalismo contemporâneo. Em um momento histórico no qual Marx associa, de maneira direta e irrestrita, o valor de uso de um produto às suas propriedades materiais (MARX, 1996, p. 166), o curso da história demonstrou como a dimensão virtual dos produtos e das relações humanas reinventou essa lógica e reorganizou o capital de um modo que o autor não teria condições históricas de supor.

Como constatação desse processo, podemos observar a análise que o pensador faz sobre a relação de valor de troca entre as mercadorias. Para Marx, o que resta ao final e como unidade de medida entre objetos distintos é o trabalho humano empregado na confecção daquela mercadoria. Embora Karl Marx considere que, nesse momento da mercadoria, o exercício do trabalho está em caráter abstrato, ainda tal abstração é, na verdade, a perda do rastro objetivo do trabalho, que se fantasmagoriza na mercadoria, mas que, em sua natureza, é concreto. A análise de valoração da mercadoria nesses parâmetros está aquém do arcabouço necessário para que se possa compreender como, atualmente, as empresas constituem seu valor de mercado. Fenômenos como as grandes corporações, que vendem seus produtos a exorbitantes margens de lucro, ou grandes portais virtuais, como o Facebook e o Twitter, que, a princípio, não estão diretamente relacionados à produção ou venda de mercadorias, não encontram explicações justificáveis para seus valores em nada material; aquilo que valem está diretamente associado à capacidade de produzir a força simbólica de sua marca ante os consumidores e, nesses casos específicos, na capacidade que têm de oferecer espaços estratégicos para outros anunciantes fortalecerem suas marcas.

Desse modo, se o valor comum que determina o valor de troca entre as mercadorias estava, no começo do desenvolvimento do capital, associado ao emprego da força de trabalho humano, parece-nos que, historicamente, tal processo foi reconfigurado e seria plausível afirmar que, atualmente, essa mediação está pouco relacionada com o emprego 
do trabalho humano sobre a mercadoria. O imperativo da mercadoria se tornou a sua imagem. Há ainda, sob esse moderno cenário, uma nova inversão: se o trabalho concreto se fantasmagorizava no valor da mercadoria, agora, é a imagem que se objetifica em seu valor.

Observemos, então, quais são as estratégias metodológicas expostas por Marx para compreender a determinação matemática do valor da mercadoria em seu tempo. Tal lógica é exposta em suas teses pelo conceito do quantum:

É, portanto, apenas o quantum de trabalho socialmente necessário ou o tempo de trabalho socialmente necessário para produção de um valor de uso o que determina a grandeza de seu valor. A mercadoria individual vale aqui apenas como exemplar médio de sua espécie. Mercadorias que contêm as mesmas quantidades de trabalho ou que podem ser produzidas no mesmo tempo de trabalho têm, portanto, a mesma grandeza de valor (MARX, 1996, p. 169).

Parece que o quantum da mercadoria sempre estará, em alguma medida, atrelada às características materiais de sua produção, como o tempo social médio de produção e seus custos, valor da matéria-prima ou custo da mão de obra, entre outros. Tal peculiaridade pode ser observada, por exemplo, no fluxo migratório das grandes indústrias para países asiáticos, nos quais essas variáveis são mais favoráveis às corporações. É também a composição dessas determinantes que explica, em grande medida, as elevadas taxas de crescimento alcançadas recentemente pela China, cujas regulamentações internas permitem às grandes corporações explorarem os aspectos materiais da produção em níveis desumanos.

Ainda segundo Marx, a determinação do quantum tem como dimensão fundamental aspectos como o tempo e a força de trabalho:

Genericamente, quanto maior a força produtiva do trabalho, tanto menor o tempo de trabalho exigido para a produção de um artigo, tanto menor a massa de trabalho nele cristalizada, tanto menor o seu valor. Inversamente, quanto menor a força produtiva do trabalho, tanto maior o tempo de trabalho necessário para a produção de um artigo, tanto maior o seu 
valor. A grandeza do valor de uma mercadoria muda na razão direta do quantum, e na razão inversa da força produtiva do trabalho que nela se realiza (MARX, 1996, p. 85).

Todavia, por si só, o manejo dessa tensão não resolve a equação do quantum da mercadoria contemporânea.

Os aspectos físicos da produção da mercadoria têm cada vez menos relação com a determinação de seu valor. Sua produção enquanto imagem assume tal papel. Como ilustra Marcuse (1981, p. 21):

No processo de automação, o valor do produto social é determinado em grau cada vez mais diminuto pelo tempo de trabalho necessário para a sua produção. Consequentemente, a verdadeira necessidade social de mão de obra produtiva declina, e o vácuo tem de ser preenchido por atividades improdutivas. Um montante cada vez maior do trabalho efetivamente realizado torna-se supérfluo, dispensável, sem significado. Embora essas atividades possam ser sustentadas e até multiplicadas sob uma administração total, parece existir um teto para o seu aumento. Esse teto, ou limite superior, seria atingido quando a mais-valia criada pelo trabalho produtivo deixa de ser suficiente para compensar o trabalho não-produtivo.

Nesse sentido, podemos observar como os produtos cujas marcas têm maior alcance não são propriamente os que equilibram melhor a relação de força produtiva de trabalho e tempo de trabalho exigido. Marcas que têm maior índice de massa de trabalho cristalizada em seu produto e ainda exercem uma flexão de lucros que torna seu produto mais barato do que uma segunda marca operacionalizada de maneira inversamente proporcional tendem a ser preteridas pelos consumidores se não tiverem projeção imagética igual ou superior à segunda opção.

Regressando nossa análise à produção de valor de um produto, parece evidente que o emprego dos mesmos esforços e custos para a fabricação de produtos concorrentes da mesma natureza gerará um valor de mercado díspar, no qual obterá maior lucro aquele que tiver uma marca de maior expressão entre seus consumidores. Assim sendo, se faz necessário pensar no quantum sensorial do produto, ou seja, quais ideias, símbolos, sentimentos e códigos sociais estão associados a esse produto em relação 
aos consumidores. Para tanto, a pressão concorrencial impele à ferocidade imagética do capital, no qual o jogo estético de sedução é o motor da lucratividade.

Na crítica ao modelo capitalista, Marx expõe a compreensão de que a determinação do valor da mercadoria está entremarcada pelas peculiaridades de um contexto histórico-cultural específico:

O produto de trabalho é em todas as situações sociais objeto de uso, porém apenas uma época historicamente determinada de desenvolvimento - a qual apresenta o trabalho despendido na produção de um objeto de uso como sua propriedade "objetiva", isto é, como seu valor - transforma o produto de trabalho em mercadoria. Segue daí que a forma simples de valor da mercadoria é ao mesmo tempo a forma mercadoria simples do produto do trabalho e, que, portanto, também o desenvolvimento da forma mercadoria coincide com o desenvolvimento da forma valor (MARX, 1996, p. 189).

Todavia, o que caracterizava o uso social da mercadoria a seu tempo era um cenário distinto de nossa contemporaneidade e, portanto, demanda um olhar renovado. Embora toda significação social seja, em certa medida, assentada por suas forças simbólicas, como a cultura, seus valores e costumes, o caráter essencialmente estético do capital produz um novo conjunto de vetores que guiarão o processo de determinação social para a convergência determinada da reificação e perpetuação da lógica vigente. A reprodução simbólica é, assim, a sofisticação estética das travestidas relações de antagonismo social.

A invenção constante de novas demandas de consumo, estratégia de subsistência do sistema, já não permite a associação direta entre mercadoria e seu fim. No contexto de uma sociedade excitada pelos estímulos imagéticos, a necessidade destacada por Marx para a transformação do produto em mercadoria, que passa essencialmente pela criação de um valor de uso social para o produto, demanda que tal processo seja constituído em sua dimensão estética. Há de se criar não somente a mercadoria, mas também o desejo de consumi-la; para tal, a indústria cultural despende um arsenal de argumentos semióticos que comporão 
o cenário da irracionalidade necessária para o florescer da compulsão ao consumo. A relação entre a capacidade de produção social do consumo está diretamente relacionada à capacidade de justificar a lucratividade da mercadoria.

Está inaugurado aqui o estágio no qual o dinheiro, capital objetivado, deixa de ser o mediador uno e absoluto das mercadorias. A consubstanciação do ser em parecer requer, pela lógica concorrencial de um capitalismo predominantemente estético, que o produto apareça. Estabelecer um significado atrativo ao público pode, por si só e sem nenhuma materialidade justificável, conduzir ao consumo.

Em seu livro Por Deus, pela pátria e pela Coca-Cola, Mark Pendergrast relaciona o sucesso da companhia Coca-Cola a seu pioneirismo na observação desse aspecto moderno da mercadoria. Segundo o autor, o grande investimento em propagandas feito pela companhia em meados dos anos 1890 possibilitou que seu produto, cujo custo total de produção era inferior a dez cents, fosse vendido a um dólar (PENDERGRAST, 1993, p. 28).

Pendergrast observa ainda uma importante característica do fenômeno comercial da Coca-Cola:

Além disso, sabia que sem muita publicidade poucos comprariam remédios, que não eram produtos essenciais. Ele tinha que ser um vendedor. Por isso, não é de admirar que o mascate de panaceias dominasse as despesas com publicidade, na Idade de Ouro. Os fabricantes desses remédios foram os primeiros homens de negócios americanos a reconhecer o poder da frase e da palavra chamativa, do logotipo e da marca registrada identificáveis, da recomendação de celebridades, do apelo ao status social, da necessidade de continuar a "usá-lo sempre". Por necessidade, foram os primeiros a vender imagem, em vez de produto (PENDERGRAST, 1993, p. 28).

Esse pioneirismo revela a necessidade de atualização do conceito clássico de quantum do produto. Pelo exemplo histórico da Coca-Cola, está evidenciada a dimensão imagética que viria a preponderar no capital moderno. Concomitantemente, a constatação de que um determinado 
produto não atende a nenhuma demanda objetiva gera a conclusão de que tal demanda pode e deve ser produzida - como constata Pendergrast ao citar a carta do publicitário William C. D’Arcy, datada de 1942, na qual afirma: "Coca-Cola não é um artigo essencial, como gostaríamos que fosse. É uma ideia - é um símbolo - é uma marca inspirada pelo gênio" (PENDERGRAST, 1993, p. 8). Destaca-se, assim, o deslocamento das propagandas de seu lugar de má fama para a centralidade da constituição da mercadoria e de seu valor.

O ponto de convergência fundamental desse processo histórico, que reverberará na constituição determinada de uma nova identidade da semicultura, é a reconfiguração da relação de valor estabelecida pela mercadoria. Karl Marx analisava da seguinte maneira a relação em sua época:

Entretanto, a forma individual de valor passa por si mesma a uma forma mais completa. Por meio da mesma, o valor de uma mercadoria é certamente expresso apenas em uma mercadoria de outro tipo. Qual é, porém, a espécie dessa segunda mercadoria, se casaco, se ferro, se trigo etc., é totalmente indiferente. Assim, conforme ela entre numa relação de valor com esta ou aquela outra espécie de mercadoria, surgem diferentes expressões simples de valor, de uma mesma mercadoria. O número de suas possíveis expressões de valor é apenas limitado pelo número de espécies de mercadorias diferentes dela. Sua expressão individualizada de valor converte-se, portanto, em uma série constantemente ampliável de suas diferentes expressões simples de valor (MARX, 1996, p. 189).

Dessa maneira, o autor categorizava o valor através de mediações relacionais expressas em uma quantificação matemática objetiva. Porém, o processo histórico composto que deu origem à atual forma de capitalismo transnacional demandou formas identitárias e mercadológicas que, para além do tipo do produto, estabeleceram valores para as marcas. Assim, consolida-se paulatinamente o processo econômico que tira o valor da natureza do produto para delegá-lo ao seu poder simbólico de marca. Em decorrência, comparações abstratas e generalistas perdem o sentido nesse contexto. A dimensão da relação de valor deixa de orbitar 
de um produto para outro e passa a estabelecer vínculos entre o espírito dos produtos e os consumidores. À medida que esse processo acirra seu caráter imaterial, a determinação dos valores se dará pela capacidade de se reproduzir, em sentido ideológico, na subjetividade do interlocutor. Paulatinamente, esse processo imprime no sujeito uma forma linguística específica e encontra, no outro polo de sua relação dialética, o homem fragilizado pelo aparato feroz e cintilante da indústria cultural.

Há de se considerar que o caráter en passant das propagandas na obra magna de Karl Marx é reflexo de como o autor compreendia o capital contemporâneo confrontado com o processo embrionário da publicidade em sua época. Ainda hoje, seu exercício suscita controvérsias entre os pensadores filiados à escola marxista clássica, tendo em vista que, se apontam, de um lado, para a importância do desenvolvimento das propagandas na constituição da lógica do processo produtivo e do capitalismo moderno, como faz Joan Robinson, há análises como a de Jacob Gorender, por outro, apontando o marketing como aquele que atende a um caráter de menor relevância para a mercadoria, representando um dispositivo simbólico regulado pela pressão concorrencial. As pesquisas científicas parecem deter maior importância na constituição da mercadoria, como fica determinado pela diferenciação daquilo que era trabalho produtivo contra o trabalho improdutivo das propagandas. A dimensão exterior da demanda objetiva à produção da mercadoria está de modo a considerar as propagandas como forma de trabalho improdutivo, como fica evidente no excerto:

[...] no capitalismo avançado dos dias atuais seria errôneo deixar de qualificar a pesquisa científica e o desenvolvimento de projetos como trabalho produtivo, ao passo que o marketing e a propaganda entram, sem dúvida, no âmbito do trabalho improdutivo, pois sua utilização não é suscitada senão pela natureza mercantil e concorrencial do modo de produção capitalista (GORENDER, 1996, p. 40, grifo nosso). 


\section{Considerações finais}

O esfacelamento do vínculo ontológico do homem com o trabalho acaba por gerar não somente a alienação em relação ao produto de seu trabalho, mas também a alienação de si mesmo, na medida em que sua autorrealização não pode mais ser efetivada no trabalho. O desenvolvimento técnico do trabalho contemporâneo a Debord manteve seu poder de destituição, ainda que, para o autor, tal processo não destituísse a natureza da identidade do proletariado:

Nesse desenvolvimento complexo e terrível que conduziu a época das lutas de classes para novas condições, o proletariado dos países industriais perdeu toda a afirmação de sua perspectiva autônoma e, em última análise, suas ilusões, mas não o seu ser. Ele não foi suprimido. Permanece irredutivelmente existente na alienação intensificada do capitalismo moderno (DEBORD, 1997, p. 81).

Se há, no movimento dialético da alienação, um componente de irredutibilidade da identidade do proletariado, as condições modernas apontam para um amortecimento da percepção de quaisquer condições que se pautem pela autonomia e pela construção de uma identidade coletiva. De forma direta, o rompimento dos vínculos ontológicos entre homem e trabalho condicionam o sujeito ao processo de destituição de sua identidade. Assim sendo, o esvaziamento simbólico do exercício do trabalho parece ter encontrado aqui outra centralidade: o protagonismo de sua construção passa a ser exercido pelas propagandas. A condensação do momento social do capital possibilita a complexificação da confusão observada por Adorno e Horkheimer, em que a mercadoria se fundia com as propagandas: "A cultura é uma mercadoria paradoxal. Ela está tão completamente submetida à lei da troca que não é mais trocada. Ela se confunde tão cegamente com o uso que não se pode mais usá-la. É por isso que ela se funde com a publicidade" (ADORNO; HORKHEIMER, 1985, p. 151). Dessa maneira, o produto não é mais consequência de uma necessidade humana do trabalhador que o confecciona; em geral, sua necessidade é produzida socialmente pela 
maquinaria ideológica, sensorial, espetacular e imagética das propagandas. Essa substituição atua regulada por uma nova lógica, um condicionamento ontológico estético resultante de um contexto social no qual fervilham o avanço imperioso do espetáculo e a degradação dos meios de experiência formativa:

E tal como a força de integração do mercado nunca foi apenas uma força econômica ou nunca apenas determinou a possibilidade de se ter ou não emprego, mas sempre determinou o ser aceito ou rejeitado e, portanto, ser ou não ser, essa pressão ontológica, sob as condições gerais da pressão para emitir, se transforma numa forma estética, ao mesmo tempo em que o estético recebe, como nunca ocorreu anteriormente, um peso ontológico (TÜRCKE, 2010, p. 64).

Categorizar as propagandas como algo que não produz diretamente lucro, sendo mera despesa inerente à mercadoria, parece uma perspectiva que está em descompasso com o cerne produtivo do capital contemporâneo. Seria possível dizer que, em certa medida, a dialética materialista parece encontrar dificuldades para apreender os movimentos de um capital cujo espírito se tornou preponderante sobre a matéria. As equiparações diretas utilizadas como metáfora em O capital, revistas hoje, estariam sempre mediadas pela força do caráter simbólico da mercadoria. Comparar varas de linho a casacos ou arrobas de trigo a libras de café passaria sempre pela questão: de qual casaco estamos falando? Qual a marca do café e qual é a grife do trigo? Há ainda a necessidade de considerarmos que a valoração imposta a seus produtos por uma marca de maior impacto publicitário não é, em nenhuma medida, desdobramento objetivo de alguma característica de sua produção. A qualidade do material, o modo de produção e a remuneração paga aos empregados, o tempo e os custos necessários - nenhum desses aspectos está salvaguardado pelo valor pago pelo produto.

Seu quantum deve ser pensado, então, na configuração moderna do capitalismo, a partir do produto e de sua diferenciação; de sua intenção objetiva e de sua desejabilidade ou produção subjetiva. Sintetizando, há de se pensar a necessidade de utilizar um tênis e a necessidade de 
utilizar um Nike; a necessidade de comprar um carro e a necessidade de comprar uma Ferrari. As corporações ganham uma dimensão para além de seu próprio produto, na qual a capacidade de produção do desejo de se consumir aquela marca específica fundamenta a equação que define o quantum do produto.

As formas de resistência ao processo de alienação devem compreender a necessidade da elaboração de novas formas, humanizadoras e restituidoras, de dar ao homem um sentido ontológico, seja por novos modelos na relação homem-trabalho,seja por substitutos que estejam em outros espaços, mas que, ao contrário da força aplicada pelas propagandas, movam os sujeitos rumo a uma compreensão mais crítica de mundo, possibilitando novos meios de enfrentamento do modelo vigente.

\section{Referências}

ADORNO, T. W.; HORKHEIMER, M. Dialética do esclarecimento: fragmentos filosóficos. Trad. Guido Antonio de Almeida. Rio de Janeiro: Zahar, 1985.

AGUIAR, J. V. Do material e do simbólico. Revista do Departamento de Sociologia da Flup, v. 20, n. 1, p. 85-108, 2010.

DEBORD, G. A sociedade do espetáculo. Trad. Estela dos Santos Abreu. Rio de Janeiro: Contraponto, 1997.

ENGELS, F. O papel do trabalho na transformação do macaco em homem. São Paulo: Global, 1990.

GORENDER, J. Apresentação. In: MARX, K. O capital. v. I. livro primeiro. Lisboa: Editorial Progresso, 1996.

MARCUSE, H. Eros e civilização: uma interpretação filosófica do pensamento de Freud. 8. ed. Rio de Janeiro: Zahar, 1981.

MARX, K. O capital. v. I. livro primeiro. Lisboa: Editorial Progresso, 1996.

PENDERGRAST, M. Por Deus, pela Pátria e pela Coca-Cola. Rio de Janeiro: Ediouro, 1993.

TÜRCKE, C. Sociedade excitada: filosofia da sensação. Trad. Antonio A.S. Zuin, Fabio A. Durão, Francisco F. Fontanella e Mario Frungillo. Campinas: Unicamp, 2010. 


\section{Sobre os autores}

Marsiel Pacífico - Doutor em Educação (UFSCar), professor adjunto no Departamento de Métodos e Técnicas (Ufam).

Luiz Roberto Gomes - Doutor em Educação pela Universidade Estadual de Campinas (Unicamp), professor associado da Universidade Federal de São Carlos (UFSCar) e professor permanente do Programa de Pós-graduação em Educação da Universidade Federal de São Carlos (PPGE/UFSCar).

Data de submissão: 16/06/2018

Data de aceite: 26/01/2019 